\title{
HUMBOLDT, UN PRUSIANO EN LA CORTE DEL REY CARLOS IV*
}

POR

\author{
MIGUEL ÁNGEL PUIG-SAMPER \\ Centro de Estudios Históricos, CSIC
}

El estudio del paso de Alejandro de Humboldt por España y especialmente por Madrid ha sido tradicionalmente uno de los aspectos más olvidados en la historiografía humboldtiana. La repetición de los pocos datos que él mismo ofreció en su obra y la falta de documentos ha hecho insuficiente la explicación de cómo fue aprobado su viaje por el rey Carlos IV, con la intervención del ministro Mariano Luis de Urquijo y del embajador de Sajonia, barón de Forell. En el presente trabajo se estudia la preparación de su viaje americano y su aprobación en la Corte española, aportando la Memoria presentada — hasta ahora «perdida»-, la autobiografía que elevó a las autoridades y el aval de Philippe de Forell. Asimismo se analizan sus relaciones con los científicos españoles en Madrid y el perfil del grupo que le ayudó a conseguir sus objetivos.

Quizá uno de los aspectos más desconocidos del famoso viaje de Alejandro de Humboldt sea el de su paso por España y más aún el del período que pasó el sabio prusiano en la corte madrileña para gestionar el viaje americano en compañía de Aimé Bonpland. Aunque se ha especulado mucho sobre las intenciones de Humboldt al llegar a Madrid, tras el fracaso de su viaje con el capitán Baudin y el posterior a Africa, lo cierto es que según la carta que dirigió desde Madrid a Reinhard y Christiane von Haeften el 28 de febrero de 1799, en agosto pensaba trasladarse a Tenerife para desde allí viajar a las Antillas danesas, donde se en-

\footnotetext{
SIGLAS UTILIZADAS:

AHN, Archivo Histórico Nacional, Madrid

ARJB, Archivo del Real Jardín Botánico, Madrid

AGI, Archivo General de Indias, Sevilla

* Quiero agradecer la colaboración en la traducción y envíos de materiales a José María Artola, Luis Alvarez, Salvador Bernabéu, Michael Zeuske y Ulrich Mücke.
} 
contraban los Keutsch ${ }^{1}$. Como se ha repetido en numerosas ocasiones, el propio Humboldt daba la clave del cambio de intenciones en el texto redactado más tarde en su Viaje a las regiones equinocciales del Nuevo Continente:

«Llegado a Madrid, tuve pronto la ocasión de felicitarme por la resolución que habíamos tomado de visitar la Península. El barón de Forell, ministro de la Corte de Sajonia ante la de España, me atestiguó una amistad que se me hizo infinitamente útil. Unía él a sus extensos conocimientos en mineralogía el más puro interés en empresas propias para favorecer los progresos de la ilustración. Me hizo entrever que bajo la administración de un ministro ilustrado, el caballero don Mariano Luis de Urquijo, podía yo esperar obtener el permiso de visitar a mis costas el interior de la América española. Tras las contrariedades todas que acababa de experimentar, no vacilé un instante en proseguir esta idea» ${ }^{2}$.

\section{EL BARÓN PHILLIP DE FORELL}

Phillip de Forell había llegado a Madrid como embajador de Sajonia en 1791, presentando sus credenciales, firmadas por Federico Augusto, ante el rey Carlos IV el 22 de agosto $^{3}$. La primera impresión producida en el monarca español, hijo de María Amalia de Sajonia, aparece recogida en una carta a su sobrino el príncipe Antonio de Sajonia, a quien comentaba «Le Ministre me paroit un très digne sujet» 4 , lo que no impidió que dos años más tarde le fuera retirada la confianza como embajador por el mismísimo Godoy por haber protestado Forell por la detención de su criado Pierre Callas, acusado de difundir ideas en favor de la democracia y el jacobinismo, siendo sustituido temporalmente por Carlos Enrique Balckes.

Según un informe del profesor de mineralogía Cristiano Herrgen, fue precisamente la vuelta a Sajonia de Forell lo que permitió que se conocieran en Europa las riquezas mineralógicas de España y que comenzasen a solicitarse colecciones de todas partes, lo cual ya era posible por el establecimiento que existía en Madrid regentado por la familia alemana Thalacker, en la propia casa de Forell en la calle Santa Bárbara. Herrgen aclara que los Thalacker, más tarde relacionados con Humboldt, llegaron a España contratados por el conde de Aranda procedentes de Bagnères de Luchon, donde eran maestros en una fábrica de tintes de

1 Ilse JaHn y Fritz G. LANGE, Die Jugendbriefe Alexander von Humboldts 1787-1799, Berlín, Akademie-Verlag, 1973, pp. 648-649.

2 Alejandro de HumBoldT, Viaje a las Regiones Equinocciales del Nuevo Continente, Caracas, Monte Ávila Eds., 1991, T. 1, pp. 44.

3 AHN, Estado, leg. 4434.

4 AHN, Estado, leg. 4684.

5 AHN, Estado, leg. 4671.

R. I., 1999, n. $^{\circ} 216$ 
azul cobalto y esmalte azul, para ocuparse de un negocio parecido al servicio del rey de España, pero éste fue entorpecido hasta su destrucción total por las intrigas de su antiguo jefe en Bagnères y el naturalista Eugenio Izquierdo, muy ligado a Godoy. Solamente su trabajo como colectores de minerales y la ayuda de Forell permitió su instalación en España, donde dos de ellos, Juan Guillermo y Enrique Talacker, fueron contratados en 1793 por el Real Gabinete de Historia Natural, institución controlada por José Clavijo y Fajardo ${ }^{6}$, personaje muy conocido por ser el editor de El Pensador y traductor de la Historia natural, general y particular del conde de Buffon (1786-1805)7, además de por su tumultuosa vida privada - recogida en una obra por Goethe - que dio lugar a su expulsión por el marqués de Grimaldi del Archivo de la Secretaría de Estado en 17648.

En 1793 recibía Clavijo una curiosa sal estalactítica descubierta por el barón de Forell y Jacob Forster ${ }^{9}$, y este último materializaba la venta de su colección mineralógica al Real Gabinete de Historia Natural a través de sus sobrinos Cristiano y Conrado Heuland, quienes a partir de 1795 dirigirían la conocida expedición mineralógica a los reinos de Perú y Chile ${ }^{10}$.

Hay que recordar además que, antes de la presencia del barón de Forell en España, había unos relevantes antecedentes en lo que a la minería y la mineralogía se refiere, puesto que desde 1784 dirigía las minas de Almadén el sajón Juan Martín Hoppensack y en 1787 se había solicitado de las autoridades de Sajonia la contratación de un gran número de expertos en minería, fabricación de máquinas para explotaciones mineras y especialistas en mineralogía. Exactamente el 15 de abril de 1787 el encargado de negocios español, Luis de Onis, se había dirigido al Ministro Secretario de Estado de Sajonia, Stutterheim, solicitando estos especialistas cuya contratación y selección se haría por Fausto de Elhúyar, el futuro director del Colegio de Minería de México ${ }^{11}$ entonces en Freiberg, con la intervención por parte sajona del barón de Heinitz. Elhúyar seleccionó tres grupos numerosos de expertos cuyo destino sería Nueva España, Nueva Granada y Perú, los tres centros de la producción minera colonial, y entre los contratados aparecían

\footnotetext{
6 ARJB, Madrid, XIII, 2, 5, 1.

7 Sebastián de la NuEZ, José Clavijo y Fajardo (1726-1806), Las Palmas, Cabildo Insular de Gran Canaria, 1990.

8 AHN, Estado, leg. 3416, exp. 13.

9 Clifford FRONDEL, «Jacob Forster (1739-1806) and his connections with forsterite and palladium», Mineralogical Magazine, vol. 38, 1972, pp. 545-550; Peter J.P. WHITEHEAD, «Some further notes on Jacob Forster (1739-1806), mineral collector and dealer», Mineralogical Magazine, vol. 39, 1973, pp. 361-363.

10 Juan Carlos ARIAS Divito, Expedición científica de los hermanos Heuland, 1795-1800, Madrid, Cultura Hispánica, 1978.

11 José Luis PESET, Ciencia y libertad. El papel del científico ante la independencia americana, Madrid, CSIC, 1987 y «El Colegio de Minería de México» en Manuel SELLÉs, José Luis PESET y Antonio LAFuente, Carlos III y la ciencia de la Ilustración, Madrid, Alianza, 1988, pp. 233-245.
} 
los nombres de Sonneschmidt y del sueco Nordenflicht, quienes más tarde contactarían también con Humboldt en México y Perú respectivamente ${ }^{12}$.

Asimismo en los años 90 comenzó una activa marcha de becarios españoles a Freiberg, hallando en la documentación los casos de Josef de Ricaurte, Andrés Manuel del Río - el amigo de Humboldt que luego encontró en México-, Francisco Codón, Josef de Miaja, Manuel Angulo, Francisco La Garza, Diego de Larrañaga, etc... ${ }^{13}$.

A pesar de su primer contratiempo, el barón de Forell volvió a España como embajador de Sajonia en $1795^{14}$ y parece que fue el que impulsó la traducción de la Orictognosia de Juan Federico Guillermo Wiedenmann por el mineralogista alemán Cristiano Herrgen, también contratado en el Real Gabinete de Historia Natural en 1796 como colector y ascendido a profesor de mineralogía en 1798, con el aval poderoso de José Clavijo y del ministro Mariano Luis de Urquijo. Herrgen reconocía su deuda con el barón de Forell en la traducción de esta obra, que supuso la modernización de este tipo de estudios en España, así como con otros sabios como Clavijo y Cavanilles que le habían ayudado a formar un lenguaje nuevo en castellano para esta disciplina ${ }^{15}$. Asimisimo, el 20 de noviembre de 1798, Mariano Luis de Urquijo aprobaba el reglamento realizado por Herrgen y Clavijo del nuevo Real Estudio de Mineralogía, que dejaba entrever el poderoso apoyo político de que disfrutaban ${ }^{16}$.

\section{MARIANO LUIS DE URQUIJO, EL MINISTRO PROTECTOR}

El perfil biográfico del ministro Urquijo, el personaje clave en el permiso de viaje a Humboldt, es escasamente conocido y de hecho su figura ha sido muy poco estudiada, sobre todo en el período anterior a su participación en el gobierno de José $\mathbf{I}^{17}$. Nacido en Bilbao en 1768 , su primera actuación pública fue la traducción de La muerte de César de Voltaire en 1791, con una introducción

12 Arthur P. WhITAKER, «The Elhuyar Mining Missions and the Enlightenment», Hispanic American Historical Review, 31, 1951, pp. 557-585.

13 «Papeles relativos a la negociación de Mineros de que estuvo encargado D. Luis de Onis en Sajonia», AHN, Estado, Libro 166.

14 Los documentos indican que estuvo en España hasta mayo de 1802, fecha en la que se retiró a Sajonia acompañado de las numerosas colecciones mineralógicas que había hecho en España. AHN, Estado, leg. 4709.

15 ARJB, XIII, 2, 5, 1.

16 ARJB, XIII, 2, 3, 1.

17 A. de BerazA, Elogio de Don Mariano Luis de Urquijo, Ministro Secretario de Estado de España, París, Imp. de L.E. Herhan, 1820. $\mathrm{M}^{\mathrm{a}}$ del Pilar LAMARQUE, «Nota sobre Mariano Luis de Urquijo», Revista de la Biblioteca, Archivo y Museo, Ayuntamiento de Madrid, año VI, núm. XXIV, 1929, pp. 470-477; Luis SIERRA NAVA, La reacción del episcopado español ante los decretos de matrimonios del ministro Urquijo de 1799 a 1813, Bilbao, Estudios de Deusto, 1964. 
crítica sobre el estado del teatro español y la necesidad de su reforma, lo que le valió una airada actuación de la Inquisición en su contra. Sólo el ascenso a la Secretaría de Estado en febrero de 1792 del conde de Aranda, el volteriano español más conocido, logró parar el golpe momentáneamente, ya que Urquijo fue nombrado en agosto de ese mismo año Oficial de la Secretaría de Estado.

La retirada de Aranda unos meses más tarde, sustituido por Godoy, y sobre todo su destierro en 1794 parece que reavivó el proceso contra Urquijo, ya que entre sus papeles encontramos un memorial dirigido a los reyes, el 26 de junio de ese mismo año, en el que protestaba por la decisión del Tribunal de la Inquisición de hacer aparecer la traducción de La muerte de César de Voltaire en un edicto público de prohibición, con la inclusión del nombre de Urquijo como traductor, lo que según éste era una ilegalidad por no haber sido convocado por el tribunal siendo Oficial de la Secretaría de Estado, lo que indicaba que todo el proceso era una artimaña de sus enemigos políticos ${ }^{18}$. En este momento parece que la protección de su futuro enemigo Godoy, quien poco antes le había recomendado para ser ordenado caballero de la orden de San Juan de Jerusalén ${ }^{19}$, fue decisiva, ya que el proceso desaparece y un año más tarde el joven Urquijo era destinado a la Secretaría de la Embajada española en Londres, donde permaneció cerca de un año hasta su vuelta a Madrid como Oficial $1^{\circ}$ de la misma Secretaría de Estado.

Su ascenso político fue imparable, ya que el 13 de agosto de 1798 se publicaba una real orden para que se le habilitase como Secretario de Estado interino mientras durase la enfermedad del recién nombrado ministro Francisco de Saavedra, situación que se confirmó en febrero de 1799 con otro decreto que confirmaba a Urquijo en su puesto, precisamente en el momento de llegar Alejandro de Humboldt a Madrid 20 .

Según el embajador danés en la Corte española, Herman de Schubart, la reina $\mathrm{M}^{\mathrm{a}}$ Luisa protegía especialmente a Urquijo, al que el mismo diplomático atribuye en esos momentos un poder absoluto, con el apoyo de un «comité secreto» que fraguaba todas las intrigas políticas y en el que incluía al barón de Forell y al embajador holandés Johan Valckenaer. El primero, calificado por Guillermo de Humboldt ${ }^{21}$ como un pedante sajón de ideas demócratas y con mucha influencia en las instituciones eruditas españolas, trabajaba en un posible matrimonio entre el príncipe de Asturias y una princesa de Sajonia, en tanto que el último era, en opinión de Schubart, un antiguo profesor de Leyden con ideas terroristas y favorable a los revolucionarios franceses, por lo que había sido alejado de la Corte holandesa, lo que coincide con la opinión de Guillermo de Humboldt que le cali-

\footnotetext{
18 AHN, Estado, leg. 3124.

19 AHN, Estado, leg. 7212, n 35.

20 AHN, Estado, legs. 3440 y 2812.

21 Wilhelm von Humboldt, Diario de Viaje a España, 1799-1800, Madrid, Cátedra, 1998, pp. 132-133.
} 
ficaba de jacobino y con mucha influencia sobre el gobierno español, al parecer por su intervención en la concesión de créditos por los banqueros holandeses.

Schubart atribuía una gran habilidad a Alejandro de Humboldt por haberse aliado al barón de Forell y al ministro Valckenaer para conseguir su permiso de viaje a América, ya que éstos ejercían «una gran influencia en la Reina y su joven ministro». El diplomático danés apuntaba también otra relación interesante, la de Humboldt con el príncipe de Parma, casado con la infanta $\mathrm{M}^{\mathrm{a}}$ Luisa, en cuya casa le conoció y al que el sabio prusiano calificaba como una planta exótica en la Corte madrileña, por sus conocimientos científicos y literarios ${ }^{22}$.

La oportunidad de encontrar a Urquijo al frente de la Secretaría de Estado fue realmente única e importante, si tenemos en cuenta que, tras las nuevas intrigas de Godoy con la colaboración de la embajada francesa, y con el pretexto de las ofensas hechas al Vaticano por Urquijo y sus amigos jansenistas, éste fue depuesto en diciembre de 1800 para ser primero desterrado a Bilbao y más tarde, en marzo de 1801, confinado en la Ciudadela de Pamplona, en el mismo pabellón que había estado el conde de Floridablanca ${ }^{23}$, coincidiendo prácticamente con la prisión de Jovellanos en Mallorca ${ }^{24}$. A Urquijo se le relacionaba ideológicamente con el grupo al que pertenecían muchos de los amigos de Humboldt en Madrid y que tenía como centro de reunión la tertulia - acusada después de jansenista y de marcado carácter afrancesado- de la condesa de Montijo, María Francisca de Sales Portocarrero, casada en secreto en 1795 con Estanislao de Lugo, director de los Reales Estudios y hermano del diplomático canario José de Lugo, también protegido de Urquijo ${ }^{25}$. A este círculo de la condesa de Montijo también pertenecían Jovellanos ${ }^{26}$, Meléndez Valdés, Cabarrús, el obispo Tavira, los Iriarte, Campomanes, Benito Bails, Luzuriaga, Pedro de Silva, los O'Reilly, Cornel, Vargas Ponce, Mazarredo, Navarrete, etc... y se ampliaba con los contactos de la condesa en la Junta de Damas de la Sociedad Económica Matritense, a la que pertenecían

22 E. GIGAS, «Lettres d'un diplomate danois en Espagne (1798-1800)», Revue Hispanique, IX, 1902, pp. 393-436.

23 AHN, Estado, legs. 2812 y 3440.

24 Gaspar Melchor de Jovellanos, Obras Completas, Oviedo, Centro de Estudios del siglo XVIII, 1986, Tomo III, pp. 620.

25 El propio hijo de la condesa de Montijo, el conde de Teba, solicitó la protección de Urquijo en noviembre de 1799 por el secuestro de libros que le había hecho la Inquisición, aunque el ministro no se ocupó especialmente del asunto, ya que el joven conde intentaba introducir las obras completas de Voltaire, la Constitución francesa, los ensayos de Locke, las obras de Buffon, la moral universal de Raynal, la historia de la Revolución francesa, etc.., obras que sin duda podían comprometerle ante el Santo Oficio. AHN, Estado, leg. 3124.

26 La ideología científica de este grupo puede observarse en el discurso pronunciado por Jovellanos el 1 de abril de 1799 en el Instituto Asturiano sobre el estudio de las ciencias naturales, en el que se pronunciaba por el estudio directo de la naturaleza y la búsqueda de sus leyes. Véase Ángel del RÍO (ed.), Jovellanos. Memoria del castillo de Bellver. Discursos-Cartas, Madrid, Espasa-Calpe, 1969, pp. 114-149.

R. I., 1999, n. ${ }^{\circ} 216$ 
entre otras la viuda de José Gálvez, marquesa de Sonora, y la condesa de Gálvez, a una de las que se refiere Humboldt al hablar de su estancia en Madrid27, así como la marquesa de Someruelos, la mujer del capitán general que recibió a Humboldt en La Habana ${ }^{28}$.

LA RECEPCIÓN DE HUMBOLDT EN LA CORTE Y EL MEMORIAL «PERDIDO» DE SU VIAJE

Según la carta ya citada de Humboldt a von Haeften, el sabio prusiano llegó a Madrid el 23 de febrero de 1799 y debió alojarse en casa del encargado de negocios de Prusia, Tribolet-Hardy, en la calle de Cantarranas, según figura en la dirección que daba a su amigo para la correspondencia. No hay muchas noticias de estos primeros días, aunque en la misma carta Humboldt comentaba que había iniciado sus visitas al Real Jardín Botánico de Madrid, donde podía estudiar las plantas americanas, y dice estar entre hombres cultivados, algo que comentaremos más tarde ${ }^{29}$.

Sobre su audiencia en la Corte española, ha quedado el testimonio que él mismo recuerda en su Viaje a las Regiones Equinocciales del Nuevo Continente:

«Fui presentado a la corte de Aranjuez, en el mes de marzo de 1799. El rey se dignó acogerme con bondad. Le expuse los motivos que me inducían a emprender un viaje al nuevo continente y a las islas Filipinas, y presenté una memoria sobre esta materia al secretario de Estado. El caballero de Urquijo apoyó mi solicitud y logró allanar todos los obstáculos. El proceder de este Ministro fue tanto más generoso cuanto no tenía yo nexo ninguno personal con él. El celo que mostró constantemente para la ejecución de mis proyectos no tenía otro motivo que su amor por las ciencias. Es un deber y una satisfacción para mí consignar en esta obra el recuerdo de los servicios que me prestó» ${ }^{30}$.

La aparente desaparición de esta Memoria y la aparición de notas en borrador entre sus papeles y en los del barón de Forell, ha hecho que los historiadores humboldtianos especulasen sobre cómo fue el proceso de aprobación del viaje y

\footnotetext{
27 En una carta de Humboldt al ingeniero Miguel Constanzó, fechada en México el 22 de noviembre de 1803, le comentaba sus visitas en Madrid a esta casa de la «Sra. Gálvez», así como a la de los O'Reilly y a la del marqués de Iranda. Véase José Omar MONCADA MAYA, El ingeniero Miguel Constanzó. Un militar ilustrado en la Nueva España del siglo XVIII, México, UNAM, 1994, pp. 332.

28 Paula de Demerson, María Francisca de Sales Portocarrero, condesa de Montijo. Una figura de la Ilustración, Madrid, Editora Nacional, 1975.

29 JAHN y LANGE, [1], pp. 648-649.

30 HumboldT, [2], pp. 44-45.
} 
sobre el contenido de la citada Memoria presentada a Urquijo, confundiendo las notas autobiográficas y las directrices de Humboldt para su permiso de viaje con la memoria oficial ${ }^{31}$. Nuestra paciente búsqueda en los archivos ha dado su fruto y aclara estos puntos que habían quedado oscurecidos en la biografía de Alejandro de Humboldt, tras encontrar esta Memoria, junto a otros documentos, en los papeles correspondientes a Sajonia en la sección de Estado del Archivo Histórico Nacional de Madrid ${ }^{32}$.

El primer documento relevante es una carta del barón de Forell (Anexo I), fechada en Aranjuez el 11 de marzo de 1799, y dirigida a Mariano Luis de Urquijo, en la que el embajador de Sajonia presentaba el proyecto de Humboldt - Consejero Superior de Minas de S.M. prusiana y sabio conocido en toda Europa-, convencido de que el permiso para visitar los dominios españoles en América daría como fruto un gran avance en los conocimientos científicos del mundo natural. Forell solicitaba la protección de Urquijo, que ya había dado pruebas de su interés en el progreso de las ciencias, tanto para Alejandro de Humboldt como para Aimé Bonpland, sólo mencionado, sin su nombre, como secretario y copista. Asimismo, el embajador pedía que se entregase la memoria al rey Carlos IV y en caso de aprobación, solicitaba la expedición de los pasaportes y de cartas de recomendación necesarias para que el sabio prusiano pudiera pasar a América con los instrumentos adecuados para sus observaciones. Además y como última recomendación, el barón de Forell enviaba a Urquijo junto a la Memoria una Noticia sobre la vida literaria de Mr. de Humbold (sic), escrito por el barón de Forell aunque firmado por Fréderic Alexandre de Humboldt y fechado en Aranjuez el 11 de marzo de 1799, documento autobiográfico que también se conserva (Anexo II) y cuyo borrador ha dado origen a las confusiones ya reseñadas, aunque es cierto que ambos documentos formaban parte de la petición de Humboldt al rey de España, por lo que el error podría considerarse sólo parcial.

31 Entre la numerosa bibliografía humboldtiana citaremos aquellos que se han ocupado del tema y son más relevantes. Karl BRUHNS, Alexander von Humboldt, Osnabrück, Otto Zeller Verlag, 1969, 2 vols., en una de las contribuciones más antiguas (el original es de 1872) y más importantes en la bibliografía sobre Humboldt, daba por perdida la Memoria, aunque especulaba con la posibilidad de encontrarla en el Archivo de Simancas (Vol. 1, pp. 272). Amando MELón, Alejandro de Humboldt, su vida y obra, Madrid, Ediciones de Historia, Geografía y Arte, 1960, pp. 48-49, se inclinaba a pensar que el descubrimiento de Lenz en el archivo de Forell del borrador de la autobiografía de Humboldt, presentado en el VII Congreso Internacional de Geografía de 1899, podía ser la perdida Memoria, cuestión que parece compartir Germán BlEIBERG, Alejandro de Humboldt y España, Tesis doctoral , Universidad de Madrid, 1958 (Archivo Histórico de la Universidad Complutense, sign. 3824) y otro de los grandes historiadores humboldtianos, Hanno BECK, Alexander von Humboldt, México, FCE, 1971, pp. 139, quien habla de la autobiografía y los proyectos en esbozo como la posible Memoria o su borrador. Por último, Charles MingueT, Alejandro de Humboldt, historiador y geógrafo de la América española (1799-1804), México, UNAM, 1985, 2 vols., en pp. 66 se inclina también por la autobiografía como posible Memoria, aunque su fuente es E. T. HAMY, Lettres américaines d'Alexandre de Humboldt (1798-1807), Paris, E. Guilmoto, 1905.

32 AHN, Estado, leg. 4709.

R. I., 1999, n. $^{\circ} 216$ 
La breve pero importante Memoria de Alejandro de Humboldt dirigida al rey decía así:

«Sire,

Penetré de cette admiration respectueuse qu'inspire un Monarque, dont la protection auguste a fait fleurir les sciences et les arts, j'ose présenter aux pieds de Votre Majesté les voeux qui m'animent. Si c'est une audace d'approcher Son Throne, l'espérance que j'ai de me rendre utile, me donne peutêtre quelque droit à Sa Clémence. Occupé depuis plusieurs années de l'etude de la Nature en Europe, je brule du desir de me transporter dans cette partie du Globe, dont les contrées les plus belles et les plus vastes jouissent des bienfaits de Votre Majesté. Les progrès qu'ont fait depuis quelque tems les sciences chimiques et physiques, l'usage des nouveaux instrumens, construits pour analyser l'Atmosphere et en connaitre des propriétés souvent aussi nuisibles à la vie de l'homme; la reunion de tous ces moyens promet une riche moisson au Naturaliste observateur. Ce n'est, Sire, que dans l'étendue immense des Royaumes soumis à Votre Sceptre, que l'on puisse étudier la Construction du Globe, mesurer les couches qui le composent, et reconnaitre les rapports généraux qui lient les êtres organisés. Ce sont ces considerations qui, de l'approbation du Roi, mon maître, m'ont conduit dans la Peninsule, ce sont elles, qui me font reclamer la Protection auguste de Votre Majesté, pour oser pénêtrer dans le nouveau monde. Je n'ai d'autres droits à Sa Clemence que le zele qui m'anime, mais ce zele est apprecié par un Souverain, qui ne Se lâsse pas de faire des sacrifices pour l'étendue des connoisances humaines. Puisse les succès de mes recherches être égal aux soins infatigables, avec lesquels je compte les faire, pour en rendre le premier hommage à Votre Majesté et pour prouver à l'Europe entiere, que je n'ai pas été tout à fait indigne de la Protection auguste, dont Elle a daigné m'honorer.

C'est dans l'espérance consolante de voir accompli des voeux, formés depuis si longtems, que j'ose me mettre aux pieds de Votre Majesté, en Lui presentant les hommages de la veneration la plus profonde et de l'obeissance la plus respectueuse, avec lesquelles je serai, jusqu'à la fin de mes jours,

Sire,

à Aranjuez

De Votre Majesté,

ce 11. de Mars,

le très-humble et très-obéissant

1799. et très-devoué serviteur,

Alexandre de Humboldt.»

Resulta extremadamente interesante que Humboldt solicitase el permiso para penetrar en el Nuevo Mundo, alegando la perfección de los nuevos instrumentos de medición de los fenómenos atmosféricos, pero sobre todo haciendo hincapié en su particular obsesión, repetida en numerosas cartas a sus amigos, la forma- 
ción del Globo, la medida de las capas que lo componen y el reconocimiento de las relaciones generales que unen a los seres organizados, objetivos que como veremos contrastan con lo señalado en el pasaporte y el permiso especial de Urquijo, que destacaban el estudio de las minas, un objetivo más práctico para los gobernantes españoles y que enlazaba a la perfección con el curriculum vitae que adjuntó Humboldt a su petición.

En éste, titulado Noticia sobre la vida literaria de Mr. de Humbold (sic) comunicada por él mismo al Barón de Forell, Alejandro de Humboldt omitía prácticamente su primera formación en su casa paterna y con sabios berlineses, que más tarde añadió en una nota autobiográfica escrita en Santafé en $1801^{33}$, para destacar sus estudios en Gotinga y Frankfurt, así como sus estudios administrativos y financieros en Hamburgo. Destacaba Humboldt que sus primeros trabajos sobre las montañas basálticas del Rhin hicieron que el director de Minas, el barón de Heinitz —el mismo que se había encargado con Elhúyar de la contratación de mineros sajones con destino a la América española - le llevase con él al departamento de Minas. Asimismo recordaba el importante viaje realizado bajo la dirección de Georg Forster por Holanda, Inglaterra y Francia, al que atribuía la mayor parte de sus conocimientos, y sus prácticas de minería en Freiberg y Harz. En su primer destino, cuyo objetivo era el estudio de yacimientos de sal, Humboldt recorrió lo que entonces era Polonia y la Alemania meridional, Hallein, Wieliczka, Berchtesgaden, etc.., antes de asumir el cargo de inspector de Minas al territorio de las colinas franconianas de alrededor de Bayreuth, donde logró que las minas dieran un rendimiento favorable para las arcas reales.

Entre sus descubrimientos, Humboldt destacó en estos primeros años de trabajo en la minería, el invento de una nueva lámpara antimefítica y de una máquina de respiración, de gran importancia para salvar vidas en las minas. Mencionaba también sus primeros trabajos botánicos, su Flora Fribergensis y su publicación sobre la fisiología química de los vegetales, traducidos ya a numerosos idiomas. En cuanto a su carrera política y diplomática, Humboldt destacó en la nota dirigida a Urquijo el papel que había tenido, por encargo del conde von Hardenberg, en las negociaciones con los franceses que dieron lugar a la Paz de Basilea.

Uno de los aspectos más interesantes de esta noticia autobiográfica de Humboldt, es su exposición sobre el interés que le movió a renunciar a su pensión oficial como Consejero Superior de Minas. Estaba decidido a recorrer otra parte del mundo y estudiar no sólo las especies y sus caracteres, sino la influencia de la atmósfera y la composición química sobre los cuerpos organizados, la formación del globo, las identidades de las capas geológicas en los países más alejados, en

33 Kurt R. BIERmann y Fritz G. LANGE, «Cómo Alejandro de Humboldt llegó a ser naturalista y explorador», Alejandro de Humboldt. Memorial en conmemoración del bicentenario de su nacimiento, Berlín, Akademie-Verlag, 1969, pp. 103-117.

R. I., $1999, \mathrm{n}^{\circ} 216$ 
definitiva se proponía según sus propias palabras estudiar las grandes armonías de la Naturaleza, aún a costa de su pequeña fortuna, que estaba dispuesto a sacrificar en beneficio del progreso de las ciencias. En cuanto a sus preparativos, Humboldt señalaba que había adquirido una selecta colección de instrumentos astronómicos y físicos para poder determinar la posición astronómica de los lugares, la fuerza magnética, la declinación y la inclinación de la aguja imantada, la composición química del aire - para lo cual había desarrollado un nuevo método con Vauquelin-, su elasticidad, humedad y temperatura, su carga eléctrica, su transparencia, el color del cielo, la temperatura del mar a gran profundidad, etc...Además, Humboldt recordaba sus experiencias sobre el galvanismo, sus estudios botánicos en Dresde y Viena, así como los químicos en París, y sus inventos: un nuevo barómetro y un instrumento que llamó anthracómetro, para la medición del ácido carbónico atmosférico.

En cuanto a sus proyectos viajeros anteriores, Humboldt recordaba la invitación del gobierno francés para viajar alrededor del mundo en la expedición dirigida por el capitán Baudin, que tanto le obsesionó, frustrada por falta de fondos, lo que le decidió a viajar por Africa para estudiar el monte Atlas. Los acontecimientos políticos en Argelia le habían hecho desistir también de este viaje, por lo que se había trasladado a la Península para solicitar la protección de S. M. Católica en un viaje a América, cuyo éxito colmaría sus deseos, una afirmación políticamente correcta aunque sólo parcialmente cierta si tenemos en cuenta sus primeras intenciones de ir a las Antillas danesas y no a la América española.

La respuesta a la petición de Humboldt aparece sobreescrita en la propia carta del barón de Forell a Mariano Luis de Urquijo con estas palabras:

«14 de marzo de 99

Digásele que el Rey le permite con gusto ir a América, a cuyo fin se pasará el correspondiente oficio a Gracia y Justicia de Indias pidiendo el Pasaporte para él, y su criado. Se añadirá al Barón que se le pasará luego que esté, y que diga a qué parte de América quiere ir primero para darle cartas de recomendación para sus Jefes. Hecho en 15 de marzo $99 .{ }^{34}$

El mismo día 15 el barón de Forell recibía un oficio de Urquijo comunicándole que se concedía el permiso al barón de Humboldt para el estudio de las minas y otros descubrimientos que proponía, por lo que le avisaba que le entregaría a él el pasaporte de Humboldt y Bonpland, que seguía siendo calificado de criado, así como las cartas de recomendación para los generales y comandantes de las diversas provincias ${ }^{35}$. La continuación del trámite administrativo se registra en

\footnotetext{
34 AHN, Estado, leg. 4709.

35 BRUHNS, [31], pp. 272.
} 
el oficio remitido por José Antonio Caballero, ministro de Gracia y Justicia de España e Indias, a Mariano Luis de Urquijo unos días más tarde:

«Exmo. Sr.

Remito a V. E. el adjunto Pasaporte, que me pidió en Oficio de 16 del corriente para que el Sr. Hunlbald (sic), Prusiano, y su Secretario, puedan pasar a la América a continuar el estudio de Minas, y perfeccionarse en el conocimiento de otros descubrimientos; a fin de que V.E. le de la dirección correspondiente.

Dios guarde a V.E. muchos años, Aranjuez

18 de Marzo de 1799

Josef Antonio Caballero» 36

Por el sobreescrito que aparece en este documento sabemos que Urquijo remitió al día siguiente el pasaporte al barón de Forelli37, quien debió preguntar a Humboldt sobre los puntos que quería que se incluyesen en el salvoconducto que iba a preparar Urquijo, ya que en un escrito del sabio prusiano al embajador de Sajonia, le indicaba claramente los puntos que debían incluirse: el nombre de su amigo y secretario Bonpland, que aparece como Alexandre en vez de Aimé, que le acompañaba para ayudarle en las investigaciones, que pensaba viajar de La Coruña a Puerto Rico, Cuba, México, el Reino de Nueva Granada, Perú, Chile y Buenos Aires, aunque quería que figurasen también las Filipinas por si la vuelta la hiciese por las Indias Orientales, que aparecieran mencionados los instrumentos de física y de astronomía, que le fuera permitido hacer toda clase de observaciones de historia natural y de física, incluyendo la recolección de plantas, animales y minerales, la medición de la altura de las montañas, las observaciones astronómicas, etc.., que se le prestase toda la ayuda necesaria para cumplir con la invitación de reunir objetos de historia natural para el Real Gabinete de Historia

36 AHN, Estado, leg. 4709.

37 El texto del pasaporte del ministro Caballero, que aparece reproducido en BRUHNS, [31], p. 456, y fotográficamente en Douglas BotTING, Humboldt y el Cosmos, Barcelona, Serbal, 1981, p. 56, dice:

«D. Josef Antonio Caballero Campo, y Herrera, Caballero Pensionado de la Real y distinguida Orden de Carlos Tercero, del Consejo de Estado de S. M. y Secretario del Despacho Universal de Gracia y Justicia de España é Indias.

Por quanto el Rey ha concedido licencia á Sr. Hunlbald (sic), Prusiano, y a su Secretario para pasar a America á continuar el estudio de Minas y perfeccionarse en el conocimiento de otros descubrimientos-

Por tanto manda S. M. á los Jueces de Arribadas de Indias de qualesquiera Puertos de España, y demas personas á quienes corresponda, no le pongan impedimento alguno, á fin de que pueda embarcarse para el referido destino en la ocasion que mas le acomode; y á este efecto expido el presente Pasaporte firmado de mi mano. Dado en Aranjuez a diez y ocho de Marzo de mil setecientos noventa y nueve.

Josef Antonio Caballero»

\section{R. I., 1999, n. $^{\circ} 216$}


Natural y los jardines reales y su envío, así como que se le recibiera en todas partes en los edificios de Su Majestad Católica ${ }^{38}$.

Perfectamente de acuerdo con estas instrucciones de Humboldt, Mariano Luis de Urquijo extendía poco después un segundo pasaporte o salvoconducto mucho más detallado que el de oficio firmado por Caballero:

«Don Mariano Luis de Urquijo Caballero pensionista de la real y distinguida orden española de Carlos III, del Consejo de Estado de S. M. su embajador extraordinario y plenipotenciario nombrado cerca de la República Bátaba, y encargado interinamente del despacho de la primera Secretaría de Estado.

$=$ Por quanto ha resuelto el Rey, que Dios guarde, conceder pasaporte a Don Alexandro Federico Barón de Humboldt, consejero superior de Minas de S. M. el Rey de Prusia, para que acompañado de su Ayudante o Secretario Don Alexandro (sic) Bonpland, pase a las Américas, y demás posesiones ultramarinas de sus dominios a fin de continuar el estudio de minas, y hacer colecciones, observaciones, y descubrimientos útiles para el progreso de las ciencias naturales; por tanto ordena S. M. a los Capitanes Generales, Comandantes Gobernadores, Intendentes, Corregidores, y demás Justicias o personas a quienes tocase, no pongan embarazo alguno en su viage al expresado Don Alexandro Federico Barón de Humboldt, ni le impidan por ningún motivo la conducción de sus instrumentos de Física, Chímica, Astronomía y Matemáticas, ni el hacer en todas las referidas posesiones las observaciones y experimentos que juzgue útiles, como también el colectar libremente plantas, animales, semillas, y minerales, medir la altura de los montes, examinar la naturaleza de éstos, y hacer observaciones astronómicas, pues por el contrario quiere el Rey que todas las personas a quienes corresponda den al expresado D. Alexandro Federico y a su Ayudante todo el fabor, auxilio, y protección que necesitaren, y ademas ordena y manda S. M. a todas las personas a quienes correspondiese por razon de sus oficios que reciban y hagan embarcar para Europa con direccion a esta primera Secretaría de Estado y del despacho, y con destino al Real Gabinete de Historia natural, todos los caxones que contengan objetos naturales pertenecientes a esta Historia, y que les fueren entregados por dicho Don Alexandro Federico Barón de Humboldt a quien se ha encargado que recoja y colecte las expresadas producciones para enriquecer el Real Gabinete de Historia natural, y los Jardines Reales, que así es la voluntad de S. M. De Aranjuez a 7 de mayo de $1799=$

Mariano Luis de Urquijo» ${ }^{39}$.

38 Alejandro de Humboldt, Cartas Americanas, Compilación, prólogo, notas y cronología por Charles Minguet, Caracas, Biblioteca Ayacucho, 1980, pp. 3-4.

39 AGI, Estado, 52, N. 113. 
Analizando este texto que el propio Humboldt sólo reprodujo en parte en su Viaje a las Regiones Equinocciales del Nuevo Continente ${ }^{40}$, encontramos que se recogen todas las pretensiones de Humboldt, con la salvedad de que la supuesta invitación a recoger objetos de historia natural para el Real Gabinete de Historia Natural y los Jardines Reales, se convierte en un encargo expreso. La alegría de Humboldt por este permiso se pone de manifiesto en la carta que escribe a Willdenow el 20 de abril, curiosamente antes de su redacción definitiva, donde expresa su satisfacción por el trato de los reyes españoles y la protección del ministro Urquijo en sus planes de exploración de la América española ${ }^{41}$. Más tarde volverá a mostrar su agradecimiento en el texto de su Viaje, por considerar que ningún extranjero había disfrutado de tanta confianza del gobierno español y por la concesión de los dos pasaportes ${ }^{42}$, en los que por cierto no figuraba su descripción física como en el concedido por el gobierno francés en octubre de 1798 a instancias del embajador prusiano en París, Alphonse de Sandoz Rollin, para su viaje a Marsella y Argel, en el que constaba que Alejandro de Humboldt tenía por entonces 28 años, talla de 5 pies y 4 pulgadas, cabello castaño claro, ojos grises, nariz prominente, boca bastante grande, mentón bien formado, frente abierta y con marcas de viruela ${ }^{43}$.

Respecto a la financiación de su viaje, el propio Humboldt aclaró unos años más tarde al Journal de Bordeaux, que lo había hecho a sus expensas aunque con la protección magnánima del rey de España durante los cinco años que había durado el viaje $\mathrm{e}^{44}$, algo que sin duda implicaba el ahorro de determinados gastos pero no la necesidad de disponer de un presupuesto propio. Sabemos que ya desde Barcelona había solicitado a Kunth dinero para instalarse en Madrid y el 4 de abril de 1799, ya en Madrid, le comentaba que el marqués de Iranda, miembro del Consejo Real de Hacienda y uno de los hombres más distinguidos de Europa, le trataba como un padre y le facilitaría todo lo necesario para su viaje. Con este motivo escribía también cuatro días más tarde a Gustav Graf von Schlabrendorf para solicitarle los 8.500 ducados que tenía en depósito, con el fin de que se los transfiriera a Abraham Mendelssohn a París y éste al marqués de Iranda en Madrid, para invertirlos con un $28 \%$ de ganancia en unas consignaciones de México.

40 Humboldt, [2], p. 45.

41 Humboldt, [38], p. 8.

42 Habría que matizar que Humboldt se refiere frecuentemente a que uno de los pasaportes era de la Secretaría de Estado y el otro del Consejo de Indias, siendo en realidad este último -el firmado por Caballero-de la Secretaría de Gracia y Justicia de España e Indias, como ya comentamos antes, aunque es posible que se pidiera opinión al Consejo de Indias, gobernado por entonces por Antonio Porlier y Sopranis, primer marqués de Bajamar, miembro de las Reales Academias de la Lengua y de la Historia y director de la Real Sociedad Económica de Amigos del País de Tenerife.

43 BRUHNS, [31], p. 300.

44 M. de la RoquetTe, Humboldt. Correspondance scientifique et littéraire, Paris, E. Ducrocq, 1865 , pp. 175-176.

R. I., 1999, $\mathrm{n}^{\circ} 216$ 
Unos días más tarde, Humboldt agradecía a David Friedländer ${ }^{45}$ el envío al marqués de Iranda de 30.000 reales de vellón, le solicitaba que aclarase con Kunth el envío de otras 20.000 libras y le comentaba las ventajas de su alianza financiera con Iranda, un hombre con mucha influencia en las Indias y entre cuyos parientes y amigos se encontraban personajes como O'Reilly, Las Casas, Gardoqui, etc..., cuyo crédito era muy valioso ${ }^{46}$.

\section{LAS ACTIVIDADES EN LA CORTE Y EL ENTRAMADO CIENTÍFICO}

Como ya indicamos anteriormente, uno de los personajes claves en la estancia madrileña de Alejandro de Humboldt fue José Clavijo y Fajardo, vicedirector del Real Gabinete de Historia Natural ${ }^{47}$, amigo del barón de Forell y protegido del ministro Urquijo. Fue a través de él como Humboldt pudo establecer sus primeras conexiones científicas en Madrid, comenzando por los propios alemanes que Clavijo protegía en el Real Gabinete, Cristiano Herrgen y los Thalacker. Con Clavijo y Herrgen visitó frecuentemente el Real Gabinete, donde se encontraban importantes colecciones mineralógicas y zoológicas americanas, y con el segundo conoció los pormenores de la nueva Escuela de Mineralogía ${ }^{48}$, acompañado del químico francés Louis Proust, que en esos momentos se trasladaba de Segovia —donde había dirigido la Casa de la Química del Real Colegio de Artillería- a Madrid para dirigir un nuevo Laboratorio químico creado tras la supre-

45 JAHN y LANGE, [1], pp. 648-658.

46 El marqués de Iranda era Simón de Aragorri y Olavide, quien había obtenido el título nobiliario en 1769 por concesión de Carlos III. Era Ministro honorario del Consejo de Hacienda y alcalde de Rentería, según G. DESDEVISES Du DEZERT, L'Espagne de l'Ancien Régime. Les Institutions, París, Société Française d'Imprimerie et de Librairie, 1899. Tenía una gran fortuna personal, hasta el punto de haber dado créditos importantes al gobierno francés, tal como figura en AHN, Estado, leg. 124. Como bien indica Humboldt, Simón de Aragorri era tío de Simón de las Casas y Aragorri, diplomático que había ocupado las secretarías de las embajadas en Viena, Prusia y Nápoles y había sido embajador de España en Venecia y en Inglaterra con honores de Consejero de Estado (AHN, Estado, leg. 3416). Asimismo, otro de sus sobrinos, Luis de las Casas y Aragorri, había sido Comandante general en Orán, mariscal de campo, gobernador de La Habana hasta 1795 y capitán general de Cádiz en la época del viaje de Humboldt. Otra sobrina, Rosa de las Casas hermana de los anteriores- se había casado con Alejandro O'Reilly, primer conde de O'Reilly, y era madre de Pedro Pablo O'Reilly, el segundo conde, que entabló una gran amistad con Alejandro de Humboldt.

47 Agustín J. Barreiro, El Museo Nacional de Ciencias Naturales (1771-1935), Aranjuez, Doce Calles, 1992.

48 Antonio Rumeu De ARMAS, «La Real Escuela de Mineralogía de Madrid (1789-1808)», Hispania, 142, 1979, pp. 301-335; Dolores PARRA y Francisco Pelayo, «Christian Herrgen y la institucionalización de la mineralogía en Madrid», Asclepio, XLVIII-1, 1996, pp. 163-181.

R. I., 1999, n. $^{\circ} 216$ 
sión de los de Francisco Chavaneau y Pedro Gutiérrez Bueno ${ }^{49}$. Humboldt comentó en carta a Karl von Moll que pocos químicos habían trabajado tanto como él, aunque lamentaba que publicase poco, y destacaba la protección real hacia el químico francés ${ }^{50}$, quien colaboraba frecuentemente con otro de los protegidos del momento, el químico burgalés Domingo García Fernández, quien compartía con Proust los locales de la calle del Turco donde él se ocupaba de asuntos de química aplicada y ensayos de moneda ${ }^{51}$.

Respecto a su relación con Juan Guillermo Thalacker, por entonces colector del Real Gabinete de Historia Natural, Alejandro de Humboldt fue su instructor en Madrid, tal como él mismo detallaba en cartas al barón de Forell y a Dietrich Karsten. Al primero le comentaba el 26 de marzo de 1799 que ya había tenido varias reuniones con Thalacker para estudiar las inclinaciones y declinaciones de los estratos, destacando su docilidad y su ansia por adquirir nuevos conocimientos, mayor que lo que el propio Humboldt podía darle, en tanto que a Karsten le recomendaba vivamente y le rogaba que le ayudase en la venta de minerales y en los problemas surgidos tras la muerte de Enrique Thalacker ${ }^{52}$. Asimismo, Juan Guillermo Thalacker publicó conjuntamente con Humboldt un gráfico que representaba las alturas desde el nivel del mar en Valencia hasta Madrid - tomadas por Humboldt - y de aquí a Navacerrada y San Ildefonso, en los Anales de Historia Natural ${ }^{53}$, la nueva revista científica que iba a aglutinar al grupo que apoyó a Humboldt en Madrid y a publicar las primeras novedades del viaje americano del sabio alemán.

Se ha especulado mucho sobre el origen de esta publicación científica y quizá sea Joaquín Fernández el que intuitivamente más se ha acercado a la realidad. Señalaba este autor que probablemente se habían aprobado los Anales por la intervención de Clavijo y el apoyo poderoso del ministro Mariano Luis de Urquijo, aunque le extrañaba que al frente de los editores estuviera Herrgen y no otros de

49 Ramón GaGo, «Luis Proust y la cátedra de química de la Academia de Artillería de Segovia» en Anales del Real Laboratorio de Química, ed. facsímil, Segovia, Biblioteca de Ciencia y Artillería, 1990, tomo I, pp. 5-51, y «Cultivo y enseñanza de la química en la España de principios del siglo XIX» en José Manuel SÁnCHEZ Ron (de.), Ciencia y sociedad en España, Madrid, El arquero-CSIC, 1988, pp. 129-142.

50 JAHN y LANGE, [1], pp. 681-682.

51 Domingo García Fernández había participado también en la creación del Semanario de Agricultura y Artes en 1796 con Juan Bautista Virio y Juan Antonio Melón, por encargo de Godoy, aunque poco después dejó la dirección por divergencias con los otros redactores. Fernando DíEZ RoDRíGUEZ, Prensa agraria en la España de la Ilustración. El Semanario de Agricultura y Artes dirigido a los Párrocos (1797-1808), Madrid, Ministerio de Agricultura, 1980. Actuó como censor de numerosas obras de química en la Real Academia Médica Matritense, en la que su hermano Gregorio fue vicepresidente y secretario, y en 1794 tuvo el apoyo de Bernardo de Iriarte para ocupar un puesto en los ensayos de elaboración de moneda en la calle del Turco (AHN, Estado, leg. 3022).

52 JAHN y LANGE, [1], pp. 652 y 665-666.

53 Anales de Historia Natural, núm. 1, octubre de 1799, p. 86.

\section{R. I., $1999, \mathrm{n}^{\circ} 216$}


mayor prestigio que figuraban entre los redactores como Antonio José Cavanilles, Luis Proust o Domingo García Fernández ${ }^{54}$. La explicación la daba José Clavijo y Fajardo en un oficio remitido al ministro Urquijo el 17 de junio de 1799 , cuando al solicitar la creación de la nueva revista argumentaba que puesto que en el reglamento aprobado para el Estudio de Mineralogía se daba permiso a su director, Herrgen, para imprimir en la imprenta real un papel periódico que diera a conocer las principales novedades científicas, tanto nacionales como extranjeras, proponía que se asociase a esta idea a Louis Proust, Domingo García Fernández y Antonio José Cavanilles, todos ellos suficientemente conocidos por su calidad científica, en la creación de unos Anales de Historia Natural, cuestión que explica la prioridad de Herrgen en la cabecera de la redacción. Clavijo proponía como contenidos principales la Mineralogía, la Química y la Botánica - los mismos que luego aparecerán en el real decreto de aprobación - siguiendo en los Anales de Historia Natural «el método de los Franceses en su periódico intitulado Journal des Mines» y solicitaba la protección directa del Secretario de Estado, incluso para la recepción de obras del extranjero ${ }^{55}$.

\section{ALEJANDRO DE HUMBOLDT Y CAVANILLES}

Entre los botánicos que se relacionaron con Humboldt en Madrid ${ }^{56}$, parece que fue precisamente Cavanilles el más apreciado por él por sus reconocidos conocimientos $^{57}$. El prestigio europeo de Cavanilles era indudable, tanto por sus publicaciones botánicas como por sus relaciones científicas con personalidades de la talla de Joseph Banks, el patriarca de la botánica inglesa, Antoine L. de Jussieu o Heinrich Friedich Link, profesor de Humboldt en Gotinga y futuro director del Jardín Botánico de Berlín, cargo en el que sustituyó a Carl Ludwing

54 Joaquín FERnÁNDEZ PÉREZ, «Estudio Preliminar», Anales de Historia Natural, 1799-1804, Madrid, CICYT, 1993, vol. 1, pp. 15-130.

55 ARJB, XIII, 2, 10, 1.

56 Enrique ÁlVAREZ LóPEZ, «Alejandro de Humboldt y los naturalistas españoles», Conferencias leídas en la Academia en los días 19 y 22 de octubre de 1959, con motivo del Centenario del fallecimiento de Alejandro de Humboldt, Madrid, Real Academia de Ciencias Exactas, Físicas y Naturales, 1960, pp. 129-166; «El viaje a América de Alexander von Humboldt y Aimé Bonpland y las relaciones científicas de ambos expedicionarios con los naturalistas españoles de su tiempo», Anales del Instituto Botánico A.J. Cavanilles, XXII, 1964, pp. 11-60; Amando MELóN, «Humboldt en el conocer la España peninsular y canaria», Estudios Geográficos, núms. 67-68, mayo-agosto de 1957, pp. 239-259. Un estudio ya antiguo sobre las fuentes españolas de Humboldt y su relación con los científicos españoles es el de Ramón de MANJARRÉs, Alejandro de Humboldt y los españoles, Sevilla, Est. Tip. de la Guía Oficial, 1915.

57 Francisco PELAYO y Ricardo GARILLETI, «La formación y actividades botánicas de A. J. Cavanilles», Asclepio, XLIV, 1992, pp. 129-154. Véase también el dossier dedicado a Cavanilles en la revista Asclepio, XLVII-1, 1995, pp. 135-260. 
Willdenow, otro de los amigos de Cavanilles que en mayo de 1799 le enviaba saludos para su discípulo Humboldt ${ }^{58}$. Link había conocido personalmente a Cavanilles en el viaje que realizó por España en 1797, con la recomendación expresa de Desfontaines ${ }^{59}$, antes de su paso a Portugal para realizar una Flora portuguesa en compañía del conde de Hoffmansegg, quien también fue corresponsal de Cavanilles y actuó de intermediario de los saludos de Link a su antiguo amigo Alejandro de Humboldt en marzo de $1799^{60}$.

En relación a Humboldt, también el conde de Hoffmansegg se interesó por su compatriota, y en carta a Cavanilles, el 14 de abril de 1799, se alegraba de la suerte de Humboldt, a quien recomendaba por sus trabajos mineralógicos y botánicos, demostrados en su Flora de Freiberg, así como por sus extensos conocimientos, que sin duda darían como fruto grandes descubrimientos en muchos terrenos. También mostró su curiosidad por saber si Humboldt había puesto condiciones para su viaje, si viajaba en comisión o por cuenta propia, con órdenes o sólo con permiso, con objetivos definidos o indeterminados, todo para tener prevista una solicitud similar a la de Humboldt en caso de que se frustrase el viaje que el conde de Hoffmansegg preparaba al Brasil, más aún si se confirmaba la noticia que circulaba en Portugal sobre una posible boda entre el Príncipe de Asturias y una princesa de Sajonia, lo que sin duda facilitaría cualquier petición de esa índole ${ }^{61}$.

Respecto al mundo botánico madrileño, Link consideraba a Cavanilles un hombre genial, en tanto que deploraba el talante de Casimiro Gómez Ortega, por entonces director del Real Jardín Botánico de Madrid ${ }^{62}$, una opinión quizá compartida por Humboldt aunque en sus recuerdos siempre se mostró amable con él por haberle mostrado, tanto a él como a Bonpland, los herbarios del Real Jardín Botánico, así como los de las expediciones de Ruiz y Pavón —botánicos a los que también conoció en Madrid-, los de Sessé y Mociño de Nueva España, y los de Luis Née de la expedición Malaspina. Gómez Ortega se hallaba en esos momentos en el declive de su carrera, apoyado por el subdirector honorario Andrés Pourret y su sobrino Hipólito Ruiz y enfrentado al ascenso imparable de Cavanilles, pero aún así era respetado en la corte madrileña y pertenecía a numerosas instituciones científicas europeas, entre ellas a la Royal Society, donde

58 ARJB, XIII, 4, $20,4$.

59 ARJB, XIII, 3, $19,1$.

60 ARJB, XIII, 3, 29, 6 .

61 ARJB, XIII, 3, 29, 7. Todavía el 22 de septiembre de 1800, el conde de Hoffmansegg preguntaba a Cavanilles por su compatriota Humboldt con gran interés (ARJB, XIII, 3, 29, 9).

62 Heinrich Friedich LINK, Bemerkungen auf einer Reise curch, Frankreich, Spanien und vorzüglich Portugal, Kiel, 1801; Ian RoBERTSON, Los curiosos impertinentes, Barcelona-Madrid, Serbal-CSIC, 1988, pp. 299-300.

R. I., 1999, n. 216 
había ingresado con el apoyo de R. Forster, el padre del gran amigo de Humboldt, Georg Forster ${ }^{63}$.

De hecho, Alejandro de Humboldt escribía desde Guayaquil el 13 de febrero de 1803 a José Pavón, quejándose de la falta de respuesta de sus cartas a Gómez Ortega y lamentaba las desavenecias ocurridas en Madrid, suponemos que entre el grupo de Ortega y el de Cavanilles, y comentaba que a pesar de sus envíos de plantas a Cavanilles no había tenido noticias de él ${ }^{64}$, lo que volvía a confirmar al propio Cavanilles el 22 de abril del mismo año desde México recordándole que le habían enviado varios paquetes de plantas en ocho o nueve ocasiones, además de las numerosas colecciones de minerales remitidas a Clavijo para el Real Gabinete. La explicación de esta falta de respuesta de los sabios españoles era insinuada por Humboldt, quien rogó a Cavanilles que no la incluyera en la publicación de la carta, pues suponía que «un malvado genio» sustraía sus cartas, una sospecha que podría disgustar al gobierno de España ${ }^{65}$.

Respecto a otros contactos, es muy probable que fuera Cavanilles quien pusiera en contacto a Humboldt con su amigo y paisano Juan Bautista Muñoz, quien pudo suministrarle importante documentación americanista, ya que en esos años organizaba el Archivo General de Indias - primero con el apoyo de Gálvez y luego de Porlier66 - y preparaba su inacabada Historia del Nuevo Mundo, basada en un incalculable acervo de documentos y con la intención expresa de crear una nueva historia de América con pretensiones científicas, tal como había manifestado Muñoz a Cavanilles y en sus informes reservados a las autoridades ${ }^{67}$. También es muy posible que la recomendación de Cavanilles influyera en la buena acogida de Humboldt en Nueva Granada por parte de José Celestino Mutis, quien por cierto fue el que comunicó al sabio prusiano la destitución de Gómez

63 Francisco Javier Puerto Sarmiento, Ciencia de Cámara. Casimiro Gómez Ortega (17411818), el científico cortesano, Madrid, CSIC, 1992.

64 «Carta de Humboldt a José Pavón, Guayaquil el 13 de febrero de 1803», Archivo de la Real Academia Nacional de Medicina, Madrid, serie documental $n^{\circ} 16$, leg. 42, doc. 2257. Sobre los envíos a Cavanilles, hay un oficio de Pedro Cevallos, de 23 de agosto de 1803, en el que le indica que dará instrucciones al Real Gabinete de $\mathrm{H}^{\mathrm{a}}$ Natural para que le entreguen las cartas, paquetes de semillas y esqueletos de plantas enviados por Humboldt desde México, ARJB, XIII, 2, 7, 20.

65 Efectivamente Cavanilles publicó un «Extracto de la carta que el Baron de Humboldt escribió desde México en 22 de Abril de 1803 á D. Antonio Josef Cavanilles», Anales de Ciencias Naturales, núm. 18, tomo sexto, 1803, pp. 281-287, luego traducida en Annals of Botany, I, 1805, pp. 573-576, omitiendo estas frases de sospecha y otras notas. Véase el original completo en ARJB, XIII, 3, 30, 1 .

66 Francisco de Solano, «El Archivo General de Indias y la promoción del americanismo científico» en Manuel Sellés, José Luis PeSET y Antonio LAFUENTE, Carlos III y la ciencia de la Ilustración, Madrid, Alianza, 1988, pp. 277-296.

67 Carta de Juan Bautista Muñoz a Cavanilles, de 31 de diciembre de 1783. ARJB, XIII, 5, 8, 8; «Idea de la obra cometida a Dn. Juan Bautista Muñoz, y del estado de ella», Madrid, 28 de noviembre de 1783, ARJB, XIII, 5, 8, 9; «Razón de la obra cometida a D. Juan Bautista Muñoz», Madrid, 16 de noviembre de 1785, ARJB, XIII, 5, 8, 10. 
Ortega y el nombramiento de su amigo común Cavanilles para el cargo de director del Real Jardín Botánico de Madrid68.

Otro asunto que ocupó la estancia de Alejandro de Humboldt en Madrid fue su gran interés en visitar la Casa de Campo, establecimiento real para el que se necesitaba un permiso especial. En carta al barón de Forell de 26 de marzo de 1799, con motivo de la presentación de Bonpland en Aranjuez, le recordaba su deseo de conseguir el permiso necesario, que en otra misiva indicaba que se le entregase a Herrgen ${ }^{69}$. Aunque este asunto sólo vuelve a aparecer en otra carta al mismo Forell el primero de abril, con una disculpa por lo complicado del tema, ya que el propio ministro Urquijo debería autorizar la entrada, hemos localizado el permiso concedido, que estaba redactado en estos términos:

«El Barón de Humpholtz (sic)

En 30 de Marzo de 1799.

Por orden verbal se puso la correspondiente a Don Juan Andrés del Valle, para que a dicho Barón, y a las Personas que lo acompañen, facilite el que vean la Casa del Campo, y quanto hay en dicha Real Posesión de modo que quede satisfecho de la franqueza y cortesanía con que trata nuestra corte a los sujetos de las Cortes extranjeras especialmente de su carácter» ${ }^{70}$.

\section{HUMBOLDT, LOS ASTRÓNOMOS Y LOS MARINOS ILUSTRADOS}

En cuanto a la relación de Humboldt con astrónomos, ingenieros y marinos españoles que le facilitaron datos para su posterior trabajo en América y que en algún caso colaboraron en las medidas tomadas en España, queremos destacar en primer lugar a José Chaix. Este matemático y astrónomo valenciano se había formado desde 1789 como pensionado en París, ciudad en la que coincidió con un grupo muy interesante de becarios españoles entre los que se encontraban Juan López de Peñalver, José $\mathrm{M}^{\mathrm{a}}$ Lanz, José Mendoza Ríos, etc...En 1792 participó, junto a Peñalver, en las operaciones de medición del arco de meridiano en España en una empresa dirigida por Jean Baptiste Delambre y Pierre Méchain, por encargo de la Academia de Ciencias de París, para pasar un año más tarde al Observatorio Astronómico de Madrid durante unos meses, antes de marchar a Gran Bretaña durante dos años. Al volver a Madrid fue de nuevo destinado al Observatorio, bajo la dirección de Salvador Jiménez Coronado con el que parece

\footnotetext{
68 ARJB, III, 1, 2, 38.

69 JAHN y LANGE, [1], pp. 652-654.

70 Archivo del Palacio Real, Madrid, Adm. Patrimonial, Casa de Campo, leg. 14, «Licencias para pasear y pescar en la Casa de Campo, 1799».
}

R. I., $1999, \mathrm{n}^{\circ} 216$ 
que tuvo una relación complicada ${ }^{71}$, ya que según Humboldt le impedía la utilización de los instrumentos de la institución, a pesar del prestigio reconocido de Chaix, quien figuraba en la lista de posibles académicos de la futura Academia de Ciencias diseñada por Bernardo y Tomás de Iriarte ${ }^{72}$.

Alejandro de Humboldt parece que tuvo bastante que ver con el ascenso y el prestigio de Chaix en la corte a partir de 1799, ya que se permitió recomendarle al barón de Forell para que intercediera ante el conde de Guzmán para que le destinase a la Inspección General de Caminos, lo que le permitiría mejorar la carta de Tofiño. Asimismo, Humboldt destacaba la buena preparación de Chaix, que había trabajado en los observatorios de París, Greenwich y Oxford, insinuaba la protección de Urquijo y en su alabanza hacía constar que Chaix preparaba la primera obra en castellano de un gran tratado de álgebra. Sobre su relación científica en el campo de la astronomía, Alejandro de Humboldt —que había comenzado sus observaciones en el palacio del duque del Infantado el 4 de marzodejó constancia de la misma en la carta dirigida al barón de Zach en mayo de 1799 , en la que le comentaba que había comparado sus observaciones sobre Monserrat con Chaix, con el que además colaboró en el cálculo de posición de algunas localidades como Madrid o Aranjuez ${ }^{73}$. La recomendación de Humboldt parece que fue efectiva, ya que el propio Chaix - que comenzó a publicar en los Anales de Ciencias Naturales - explicaba cómo en abril de 1799, fecha que coincide con la carta de Humboldt a Forell, había recibido el apoyo de Mariano Luis de Urquijo para conseguir los instrumentos y el local apropiado para observar el paso de Mercurio por el disco del sol, y poco después había conseguido realizar sus primeras observaciones en el Observatorio por orden directa de Urquijo y con el apoyo de Agustín de Betancourt. Asimismo su enlace con el grupo «humboldtiano» madrileño se establece de manera definitiva si consideramos sus observaciones astronómicas en la casa de Herrgen en la calle del Turco con ayuda de Martín de Párraga para establecer la posición de Madrid ${ }^{74}$.

Entre los marinos que aportaron datos para el viaje humboldtiano, aunque no hay constancia de que los conociera a todos personalmente, cabe citar a Martín Fernández de Navarrete y José Vargas Ponce, dos de los más notables eruditos de su época, muy ligados al Depósito Hidrográfico de Madrid, así como a José Mazarredo, gran amigo de Urquijo y por entonces jefe de la escuadra, y Federico Gravina, el héroe de Trafalgar y segundo del anterior. Ayudante también de Mazarredo fue José Espinosa y Tello, director desde 1797 del Depósito Hidrográfico

\footnotetext{
71 Santiago GARMA, Josep Chaix y el progrés matemàtic a principis del segle XIX, Valencia, Generalitat Valenciana, 1994; Antonio RUMEU DE ARMAS, Ciencia y Tecnología en la España Ilustrada. La Escuela de Caminos y Canales, Madrid, Turner, 1980, pp. 136-139 y 287-294.

72 AHN, Estado, leg. 3022.

73 JAHN y LANGE, [1], pp. 655 y 667-676.

74 Anales de Ciencias Naturales, núm. 7, enero de 1801, pp. 78-84, núm. 8, febrero de 1801, pp. 163-170, núm. 11, julio de 1801, pp. 131-147, núm. 12, octubre de 1801, pp. 302-321.
} 
y cuya labor fue alabada especialmente por Humboldt, quien reconoció explicítamente que le suministró valiosa información en su visita a Madrid, en la que parece que también conoció a Dionisio Alcalá Galiano, colaborador de Malaspina en su viaje alrededor del mundo ${ }^{75}$. Asimismo hay constancia de una posterior cooperación entre Humboldt y Felipe Bauzá, heredero de Espinosa en la dirección del Depósito Hidrográfico y exiliado en Londres desde 1823, a partir de 1804 , tras la conclusión del viaje por América ${ }^{76}$, aunque ya antes había comenzado la colaboración con el Depósito Hidrográfico, puesto que en abril de 1804 ya había enviado Humboldt desde La Habana algunos resultados de sus observaciones a José Espinosa, al que además agradecía la colaboración que había tenido en México de su hermano Manuel Espinosa ${ }^{77}$.

Además de los mencionados, Humboldt citará con frecuencia las mediciones de Cosme de Churruca, quien se había destacado por sus trabajos astronómicos e hidrográficos en el estrecho de Magallanes, en Trinidad y en el levantamiento de diferentes cartas de las Antillas, Ventura Barcaíztegui, que había recorrido las costas cubanas entre 1790 y 1793 para hacer el levantamiento hidrográfico de las costas y hacer un estudio de los recursos naturales del oriente de Cuba, junto a otros marinos como José del Río, Tomás de Ugarte o el reconocido astrónomo y corresponsal del Depósito Hidrográfico, José Joaquín Ferrer y Cafranga, miembro de la Sociedad Filosófica de Filadelfia ${ }^{78}$.

Realmente gran parte del trabajo hidrográfico y astronómico de estos marinos-científicos será uno de los más valiosos para la obra de Humboldt, quien recuerda frecuentemente la deuda contraída con su obra. Como ejemplo cabe citar la mención que hace en la carta que escribió a Manuel Espinosa y Tello, el hermano del director del Depósito Hidrográfico, por entonces en México:

«...diga Mr. Fleurieu y la envidia de otras naciones lo que quieran, la posteridad más remota agradecerá a los marinos españoles los inmensos y importantes trabajos que han sabido acopiar en los últimos 20 años, yo a lo menos no conozco

75 Martín Fernández de NAVARrete, Biblioteca Marítima Española, Madrid, Imp. de la Viuda de Calero, 2 vols., 1851.

76 Carlos A. BAUZÁ, «Alejandro de Humboldt y Felipe Bauzá: una colaboración científica internacional en el primer tercio del siglo XIX», Revista de Indias, LIV, núm. 200, 1994, pp. 83-106.

77 Carta de Alejandro de Humboldt a José Espinosa, fechada en La Habana el 25 de abril de 1804. Museo Naval, Madrid, Ms. 132, «Observaciones y padrones de América», tomo I, doc. 5, fols. 370-372.

$78 \mathrm{M}^{\mathrm{a}}$ Dolores GonZÁLEZ-RIPOLL, A las órdenes de las estrellas. La vida del marino Cosme de Churruca y sus expediciones a América, Madrid, Fundación BBV-CSIC, 1995; Trinidad, la otra llave de América, Caracas, Lagoven, 1992; y «Una aproximación a la expedición secreta de Ventura Barcaítegui (1790-1793) y los reconocimientos de la parte oriental de Cuba», Asclepio, XLIII-2, 1991, pp. 165-179.

R. I., $1999, \mathrm{n}^{\circ} 216$ 
otra nación que hubiese adelantado más la Astronomía naútica en publicando más mapas exactos en tan corto tiempo»79.

A mediados de mayo de 1799 abandonaban Alejandro de Humboldt y Aimé Bonpland la corte madrileña en dirección a La Coruña, donde se embarcaron en la fragata Pizarro con rumbo a Canarias y el continente americano ${ }^{80}$, donde se desarrollaría su principal obra científica y pasaría Humboldt a formar parte de la mitología nacional criolla ${ }^{81}$. Pocos meses más tarde se afianzaban las relaciones científicas con Sajonia, con la compra de libros y minerales para la Escuela de Mineralogía a través del barón de Racknitz ${ }^{82}$, y llegaba a la corte española Guillermo de Humboldt ${ }^{83}$, con una mirada sobre España muy diferente a la de su hermano ${ }^{84}$.

79 Carta de Alejandro de.Humboldt al coronel Espinosa, Manuel Espinosa y Tello, fechada en México el 8 de noviembre de 1803, Museo Naval, Madrid, Ms. 96, «Mar del Sur I», doc. 5, fols. 86-94.

80 Alejandro de Humboldt, Viaje a las Islas Canarias, Edición, estudio crítico y notas de Manuel Hernández González, La Laguna, Francisco Lemus, 1995.

81 Manuel LUCENA GIRALDO, «El espejo roto. Una polémica sobre la obra de Alejandro de Humboldt en la Venezuela del siglo XIX», Dynamis, 12, 1992, pp. 73-86; Leoncio LóPEZ-OCóN, «Un naturalista en el panteón. El culto a Humboldt en el Viejo y el Nuevo Mundo durante el siglo XIX», Cuadernos Hispanoamericanos, núm. 586, 1999, pp. 21-33; y especialmente, Michael ZEUSKE, «Humboldt y el problema de la transformación en Venezuela y Cuba (1760-1830). Ocho tesis y un apéndice teórico» en Alberto GIL Novales (de.), Ciencia e independencia política, Madrid, Ediciones del Orto, 1996, pp. 83-128. Para el caso cubano, véase Miguel Ángel PUIG-SAMPER, Consuelo NARANJo Orovio y Armando GarCía GonZÁlez (eds.), Ensayo político sobre la Isla de Cuba. Alejandro de Humboldt, Aranjuez, Doce Calles-Junta de Castilla y León, 1998.

82 AHN, Estado, leg. 4685.

83 Arturo FARINELLI, Guillaume de Humboldt et L'Espagne, Torino, Fratelli Bocca, 1924. La solicitud de permisos de Guillermo de Humboldt para visitar El Escorial y para pasaportes internos, a través del embajador prusiano conde de Rohde, en AHN, Estado, leg. 4381.

84 José María ARTOLA, «La vocación de Alexander von Humboldt y su relación con España», La imagen de España en la Ilustración alemana, Madrid, Görres-Gesellschaft, 1991, pp. 265-286. 


\begin{abstract}
ANEXO I
«Aranjuez le 11. Mars 1799

La conviction dans la quelle le soussigné se trouve des avantages réels, qui doivent résulter pour l'avancement des connoissances naturelles, des intéressans projets de Mr. de Humbold (sic), Conseiller Supérieur des Mines de S. M. prussienne, jeune savant dont la célébrité est si bien établie non seulement en Allemagne mais dans l'Europe entière, lui font espèrer, que S. E. Monsieur le Chevalier d'Urquijo, qui donne des preuves si manifestes du zele dont il est animé pour les progrès des Sciences, voudra bien accueillir et accorder Sa protection à la demande ci-jointe de Mr. de Humbold (sic), que le soussigné prend la liberté d'adresser et de recommander à Son Excellence, espérant qu'Elle daignera la mettre sous les yeux de S. M. lui accorder Sa protection, lui faire obtenir la grace, que ce Savant demande de pouvoir passer dans les vastes domaines de S. M. en Amérique, accompagné d'un seul homme de suite lui servant de Secrétaire ou Copiste.

Dans quel cas Son Excellence est priée de bien vouloir donner les ordres nécessaires, faire expédier les passeports correspondans et munir Mr. de Humbold (sic) de lettres de recommandation, qui seront jugées convenables, afin que ce Savant puisse passer en Amérique avec les instrumens nécessaires à ses observations.

Le soussigné ne seauroit mieux justifier au reste l'intérêt qu'il doit prendre à la réussite des utiles projets de Mr. de Humbold (sic), qu'en transmettant à Son Excellence la ci-jointe notice, que sur sa requisition Mr. de Humbold (sic) a bien voulu lui communiquer relativement à sa vie littéraire, à ses travaux, et à ses importantes découvertes.
\end{abstract}

Philippe Baron de Forell

A Son Excellence Monsieur le Chevalier d'Urquijo.»

(AHN, Estado, leg. 4709) 


\begin{abstract}
ANEXO II
«Notice sur la vie littéraire de Mr. de Humbold (sic), communiquée par lui même au Baron de Forell.
\end{abstract}

Après avoir joui d'une éducation tres soignée dans la maison paternelle et de l'instruction des savans les plus distingués de Berlin; j'ai fini mes études aux Universités de Goettingen et Frankfort. Destiné alors pour la partie des finances j'ai resté pendant un an à l'Academie de commerce de Hambourg, établissement destiné tant à l'instruction des négocians, qu'a celle des personnes, qui doivent servir l'Etat pour la direction du Commerce, des banques et des manufactures. Les succès peu mérité qu'eut mon premier ouvrage sur les montagnes basaltiques du Rhin, fit désirer au chef de nos mines, le Baron de Heiniz (sic), que je me vouasse à son département. Je fis delors un voyage de Mineralogie et d'histoire naturelle en Hollande, en Anglaterre et en France sous la conduite de George Forster, célèbre Naturaliste, qui avoit fait le tour du monde avec le Cap. Cook. C'est à lui que je dois pour la plupart le peu de connoissances, que je possède. De retour de l'Anglaterre j'appris la pratique des mines à Freiberg et au Harz. Ayant fait quelques expériences utiles pour l'epargne du combustible à la cuite du sel et ayant publié un petit ouvrage relatif à cet objet, (traduit en françois par Coquevert) le Roi m'envoya en Pologne et dans le midi de l'Alemagne pour étudier les mines de sel gemme de Vieliezca, Hallein, Berchtesgaden... Les plans, que je dressai, servirent pour les nouveaux établissemens des Salines de Magdebourg. Quoique je n'eusse servi alors que pendant huit mois, S. M. ayant réuni à la Couronne les Margraviats en Franconie, me nomma directeur des mines de ces provinces, dans les quelles l'exploitation avoit été negligée depuis des siècles; je restai voué à la pratique des mines pendant trois ans et le hazard favorisa tellement mes entreprises, que les mines d'Alun, de Cobolt, et mêmes celles d'or de Golderonach commencerent bientôt à devenir profitables aux caisses du Roi. Content de ces progrès, on m'envoya une seconde fois en Pologne, pour donner des renseignemens sur le parti, que l'on pourroit tirer des montagnes de cette nouvelle province, qu'on nomma delors la Prusse méridionale. Je dressai en même tems les plans pour l'amélioration des sources salées situées aux bords de la Baltique. C'est pendant ce sejour continuel dans les mines, que je fis une suite d'expériences assez dangereuses sur les moyens de rendre moins nuisible les moffettes souterraines, et de sauver les personnes asphyxiées. Je parvins à construire ma nouvelle lampe antimephitique, qui ne s'eteint dans aucun gaz, et la 
machine de respiration, instrumens qui servent en même tems aux mineurs militaires, lorsque le contremineur empêche leurs travaux par des camouflets. Cet appareil eut l'approbation du Conseil de guerre et sa simplicité l'a fait repandre très rapidement dans l'étranger. Je publiai aussi pendant cet intervalle un ouvrage de Botanique, Flora Fribergensis, la Physiologie chymique des vegétaux, traduit en plusieurs langues, et un grand nombre de Memoires de physique et de chimie, inserés en partie dans les journeaux de France et d'Anglaterre.

Du retour de Pologne ne je quittai pour long-tems le sejour des montagnes, accompagnant Mr. de Hardenberg dans ces négociations politiques, dont le Roi le chargea immediatement avant la paix de Bâle. Je le suivi aux armées, postées sur les rives du Rhin, en Hollande, et en Suisse. C'est de là, que j'eus occasion de visiter la haute chaine des Alpes, le Tirol, la Savoye et tout le reste de la Lombardie. Lorsque l'année suivante les armées françoises avancerent vers la Franconie, je fus envoyé au quartier général de Moreau pour traiter sur la neutralité de quelques princes de l'Empire, dont le Roi embrassa la defense.

Ayant un desir ardent de voir une autre partie du monde et de la voir sous les rapports de physique générale, d'étudier non seulement les espèces et leurs caractères, étude au quel on s'est voué trop exclusivement jusqu'ici, mais l'influence de l'Atmosphère et de sa composition chymique sur les corps organisés; la construction du globe, l'identités des couches dans les pays les plus éloignés les uns des autres, enfin les grandes harmonies de la Nature, je formai le souhait de quitter pour quelques années le service du Roi et de sacrifier une partie de ma petite fortune aux progrès des Sciences. Je demandai mon congé, mais S. M. au lieu de me l'accorder, me nomma son Conseiller Supérieur des Mines, augmentant ma pension et me permettant de faire un voyage d'histoire naturelle. $\mathrm{Ne}$ pouvant être utile à ma patrie dans un éloignement aussi grand, je n'ai point accepté la pension, en remerciant $\mathrm{S}$. M. d'une faveur, moins accordée à mon peu de mérite, qu'à celui d'un pere, qui jouissoit jusqu'à sa mort de la confiance la plus distinguée de son Souverain.

Pour me préparer à un voyage, dont les buts doivent être si variés, j'ai rammassé une collection choisie d'instrumens d'Astronomie et de physique, pour pouvoir déterminer la position astronomique des lieux, la force magnétique, la déclinaison et l'inclinaison de l'aiguille aimantée, la composition chymique de l'air, son élasticité, humidité et température, sa charge electrique, sa transparence, la couleur du ciel, la température de la Mer à une grande profondeur etc..

Ayant fait alors quelques decouvertes très frappantes sur le fluide nerveux et la maniere de stimuler les nerfs par des agens chymiques, d'en augmenter et diminuer l'irritabilité à son gré, je sentis le besoin de faire un étude plus particulier de l'Anatomie. Je sejournai pour cela pendant quatre mois à l'Université de Jena et je publiai les 2 volumes de mes Expériences sur les Nerfs et le procès chymique de la vitalité, ouvrage dont la traduction a paru en France. Je passai de Jena à Dresde et à Vienne pour en étudier les richesses botaniques et pour pénétrer de 
nouveau en Italie. Les troubles de Rome me firent desister de ce projet et je trouvai pendant mon sejour de Salzbourg, une nouvelle methode d'analyser l'air atmospherique, methode sur la quelle j'ai donné un memoire avec Vauquelin. Je finis en même tems la construction de mon nouveau Barometre et d'un instrument, que j'ai nommé Anthracometre, parcequ'il mésure la quantité d'acide carbonique contenue dans l'atmosphère. Pendant l'espérance de pouvoir pénétrer jusqu'à Naples, je partis pour la France, où je travaillai avec les chymistes de Paris pendant 5 mois. Je lus plusieurs Memoires à l'Institut National, contenus dans les Annales de Chimie, et j'y publiai deux ouvrages, un sur les moffettes des mines et les moyens de les rendre moins nuisibles, l'autre sur l'analyse de l'air. Le Directoire François ayant resolu de faire faire (sic) un voyage autour du monde avec 3 vaisseaux sous le Commandement du Cap. Baudin, je fus invité par le Ministre de la Marine de joindre mes travaux à ceux des Savans, qui devoient être de cette expédition. Je me preparai déjà de partir pour le Havre, lorsque le manque de fonds fit échouer ce projet. Je resolus delors de me rendre en Afrique pour étudier le Mont Atlas; j'attendois pendant deux mois mon embarquation à Marseille, mais les changemens de systême politique arrivés à Alger, me firent renoncer à ce projet et je pris la route de la peninsule pour demander la protection de S. M. Catholique dans un voyage d'Amerique, dont le succés me mettroit au comble de mes voeux.

\section{à Aranjuez ce 11 de Mars \\ Fréderic Alexandre de Humboldt} 1799»

(AHN, Estado, leg. 4709)

(El texto tiene letra del barón de Forell, en tanto que la fecha y la firma corresponde a Alejandro de Humboldt)

The study of Alejandro de Humboldt's transit through Spain and particularly Madrid, has been one of the forgotten aspects of his historiography. The reasons that would explain the approval by king Charles IV of his trip, involving the minister Mariano de Urquijo and the embassador of Sajonia, baron of Forell, are not sufficiently documented due to the scarce data that Humboldt himself offered in his work and to the absence of any other supporting documents. This work studies the preparation of his American trip and its approval by the Spanish court. It incorporates the Memorandum presented - which was «lost» until now-, the autobiography submitted to the authorities and the references given by Philippe de Forrell. Furthermore, it analyses his relationships with the Spanish scientific community in Madrid and the profile of the team that supported him to achieve his targets. 